\title{
Calculating reading ease score of patient package inserts in Iran
}

\author{
Vahideh Zarea Gavgani ${ }^{1,2}$ \\ Sedigheh Mirzadeh- \\ Qasabeh' \\ Jalal Hanaee ${ }^{3,4}$ \\ Hadi Hamishehkar ${ }^{5}$ \\ 'Department of Medical Library \\ and Information Sciences, School of \\ Management and Medical Informatics, \\ Tabriz University of Medical Sciences, \\ Tabriz, Iran; ${ }^{2}$ Tabriz Health Service \\ Management Research Center, Tabriz \\ University of Medical Sciences, Tabriz, \\ Iran; ${ }^{3}$ Department of Pharmaceutical \\ Chemistry, Faculty of Pharmacy, \\ Tabriz University of Medical Sciences, \\ Tabriz, Iran; ${ }^{4}$ Faculty of Pharmacy, \\ Near East University, Nicosia, Cyprus; \\ ${ }^{5}$ Department of Clinical Pharmacy, \\ Faculty of Pharmacy, Tabriz University \\ of Medical Sciences, Tabriz, Iran
}

This article was published in the following Dove Press journal: Drug, Healthcare and Patient Safety

Background: The patient package inserts (PPIs), which contain the necessary information about medications intended for patients, need to be expressed in a clear language comprehensible to everyone.

Objective: This study aimed to evaluate the readability and understandability of the drug package inserts for the inexpert people.

Methods: The readability of the 158 PPIs of the 33 drugs, registered and manufactured in Iran, was calculated. The main criterion for selecting PPIs to include in this study was of those topselling drugs during the year 2015 according to the Social Security Organization in Iran. The PPIs were collected from the pharmacies of the three major cities, namely, Tabriz, Ardabil and Meshgin Shahr. Then, using the Flesch-Dayani readability (FDR) tool adjusted for the Persian language, the average number of the words and syllables was counted to calculate and grade the readability score of the selected PPIs.

Results: This study showed that the average FDR readability score for all the 33 drugs is 52.52, which are graded 10th-11th. Of the PPIs, $70.89 \%$ were difficult to read, and on average, the readability of the PPIs was five times difficult than the standard ones. Only $13.92 \%$ PPIs were suitable for the 5 th -7 th grade, and $15.19 \%$ of the package inserts ranked in the 8 th -9 th reading grade.

Conclusion: A considerable number of the PPIs in Iran have low readability level and were not suitable for the inexpert readers. Since the treatment cost is very high, people tend to use medications arbitrarily or simply use old prescriptions. This study suggests the necessity of a major improvement in the readability level of the PPIs in order to ensure the usefulness of the PPIs to the majority of the consumers.

Keywords: Flesch-Dayani indicator, drug package insert, patient package inserts, readability, pharmaceutical brochures, leaflet, drug guide, Flesch-Dayani readability

\section{Introduction}

The Patient package insert (PPI) is an important source of medication information for the physicians and the patients. ${ }^{1}$ It is also an essential part of the modern drug distribution systems, as well as a tool for the patient education and health policy. ${ }^{2}$ The PPIs provide a great deal of information in the related field in the developing countries, as in these countries, access to the latest developments and up-to-date information is restricted. ${ }^{3}$ The evidence show that the information provided in the PPIs may meet the information needed by the pharmacists or the physicians, but not necessarily of those needed by the patients. ${ }^{4}$ The patients usually do not find the information they are looking for in the package inserts, and above that, the language used in the package inserts

Correspondence: Sedigheh Mirzadeh Qasabeh

Department of Medical Library and Information Sciences, Room Number 210 , School of Management and Medical Informatics, Tabriz University of Medical Science, Behind the Shahid Madani Heart Hospital, Tabriz, Iran

Tel +9891 41973248

Email se.mqas@gmail.com 
is not readable for them. ${ }^{5-7}$ Most of the patients try to read the package inserts for the information such as therapeutic indications, dosage instruction, contraindications, usage, warnings, ingredients, mechanism and side effects. ${ }^{8,9}$ Some of the patients are not aware of the exact use of the PPIs. ${ }^{9}$ Sometimes, even some people rely on the PPIs' information in order to avoid visiting a proper doctor and also avoid paying the high health expenditures; for example, in a country like Iran where the people's income is low/middle, the arbitrary use of medications such as antibiotics, anti-inflammatory medications and nonsteroidal anti-inflammatory drugs (NSAIDs) is high, because the people cannot afford the treatment expenditures. ${ }^{10,11}$ However, the patients aware of their inadequate knowledge about the side effects and unpredicted consequences of the drugs, ${ }^{12}$ they do not show any interests in reading a professional and scientific text to get more information because of its unreadability, especially those with a lower level of literacy. Therefore, the PPIs for both the over-the-counter and prescription medicines must be written in a way to be read and understood easily by everyone who requires. The suggested reading level in the literatures for general patient information is the 5th-6th level. ${ }^{13,14}$ The rules and regulations for the PPI issued by the Food and Drug Organization in Iran mandate the acceptable level of readability and understandability, not mentioning any direct reference to a constant grading. In the Persian literature, the suggested grade would have been the 5 th-6th reading level. ${ }^{10}$

The results of the studies show that the package leaflets for the prescription medicines are difficult to read, difficult to understand and even they sometimes confuse and make the patients hesitant to act. ${ }^{8}$ Despite the emphasis on the fact that the patients have the right to receive the medical information in a simple language, it is unclear to what extent the PPIs have taken into consideration this issue. The preliminary literature review has revealed that there is a research gap regarding the evaluation of the PPIs and the pharmaceutical brochures in Iran; the only evaluation done before was on the Iranian pamphlets about the patient educational leaflets in a hospital setting. ${ }^{10}$ To fill this research gap, the preset study aimed at evaluating the reading ease of the PPIs of the top-selling medications in Iran.

\section{Methods}

This cross-sectional study was carried out to assess the readability of the PPIs of the top-selling medications from March 2015 to September 2015 according to the Social Security Organization in Iran. The criteria for selecting the drugs were as follows: 1) being available in a solid form;
2) being registered in the drug generic of the Iran Food and Drug Administration (IRFDA); 3) being listed as one of the top-selling drugs according to the Social Security Organization and 4) being available in the local markets/pharmacies.

\section{Data collection}

The PPIs were gathered from the pharmacies of the three big cities: Tabriz, Ardabil and Meshgin Shahr during November 1, 2015, and March 30, 2015 (Table S1). A total number of 158 PPIs for 33 top-selling drugs were collected and assessed to provide readability score (Table S2). The PPIs belonged to 43 pharmaceutical manufacturers (names are kept confidential) and 11 treatment groups (Table S3). Among the various readability measures, the Flesch formula is one of the reliable and most used indicators for grading the reading levels. This study used the Flesch-Dayani indicator, ${ }^{15}$ the Flesch's Persian-adjusted version, for measuring and ranking the readability of the texts.

\section{Scoring methods}

The Flesch-Dayani readability ease (FDRE) formula was used to measure the readability of the PPIs. The Flesh formula is calculated by detracting the number of the length of the sentences (SL) and the length of the words/syllables (WL) from the constant number 206.835. Dayani ${ }^{28}$ redefined the constant number from 206.835 to 262.835 for the Persian text readability level. In this study, from each package insert, a sample of 100 words was randomly chosen. Then, the SL and the WL were counted manually and inserted into the Flesch-Dayani formula for calculation as follows:

Flesch - Dayani formula $=[(262.835)-0.846 \mathrm{WL})-1.015 \mathrm{SL})$

$\mathrm{SL}=\frac{\text { Number of words in text }}{\text { Number of sentences in text }}$

$\mathrm{WL}=\frac{\text { Number of letters in text }}{\text { Number of words in text }}$

According to the FDRE formula, a proper text should contain shorter sentences, fewer words and shorter syllables. The score between 60 and 70 is considered as "standard" and scores $\geq 70$ rank as "fairly easy" to "very easy". ${ }^{16}$ The Flesch reading ease table shows the description of the scores based on the Flesch reading ease assessment. The results of the calculations were compared to the table of readability (Table S4). The average score was calculated to find the readability of the PPIs in the treatment/medication groups and a single medication from the others. 
The data obtained were subject to analysis using the Microsoft Office Excel 2010. The average, maximum and minimum readability scores were gained to be reported.

This study is approved by the ethics committee of Research Department with the reference number TBZMED. REC.1394.140.

\section{Results}

The research shows that the average Flesch-Dayani readability (FDR) score for all the 33 top-selling drugs is 52.5 , which are graded from 10th to 11 th level of reading (Table 1). Approximately $70.9 \%$ of the PPIs had a reading difficulty, ranging from fairly difficult to very difficult, based on the Flesch reading ease formula. Only $13.9 \%$ of the PPIs were suitable for the 5 th-7th grade, and $15.2 \%$ of the PPIs were graded in the 8 th -9 th reading level (Table 2). There was no consistency in the readability level of either a same drug with various PPIs or all drugs of a specific factory. Among all the 158 PPIs, the most readable PPIs belonged to calcium $\mathrm{D}(\mathrm{FDR}=97.9)$ and the most difficult PPIs also belonged to calcium D (FDR = 7.34) (Table S2).

Evaluation based on the order of the generic name of the drugs showed that, on average, the ferrous sulfate with only one PPI and the readability score of FDR $=72.5$ had the maximum reading ease among the 33 drugs and the captopril with totally three PPIs and the average score of FDR $=35.5$ had the minimum readability score (Table 1 ).

However, the groupwise classification of the reading ease scores showed that the PPIs in the medication group of "Nutrition and Vitamins" with the average score of FDR = 61.8 were the easiest to read among the other pharmaceutical brochures. The PPIs of the medications in the group of

Table I Average FDR score of a drug with number of available PPIs from different factories based on the order of generic name of drugs

\begin{tabular}{|c|c|c|c|c|}
\hline Order & Generic name & Number of PPIs & Average FDR score & Predicted FDR grade \\
\hline I & Captopril 25 & 4 & 35.5 & College grade \\
\hline 2 & Calcium supplements D & 6 & 36.1 & College grade \\
\hline 3 & Diclofenac 50 & 3 & 36.7 & College grade \\
\hline 4 & Metformin hydrochloride 500 & 10 & 41.8 & College grade \\
\hline 5 & Sodium valproate & 3 & 43.4 & College grade \\
\hline 6 & Losartan potassium 25 & 6 & 43.5 & College grade \\
\hline 7 & Losartan potassium 50 & 6 & 43.5 & College grade \\
\hline 8 & Nitroglycerin & 6 & 44.6 & College grade \\
\hline 9 & Amoxicillin & 2 & 45.7 & College grade \\
\hline 10 & Hydrochlorothiazide & 2 & 46.7 & College grade \\
\hline 11 & Diclofenac & 5 & 48.1 & College grade \\
\hline 12 & Nitroglycerin 2.6 & 7 & 48.3 & College grade \\
\hline 13 & Glibenclamide & 5 & 49.1 & College grade \\
\hline 14 & Loratadine 10 & 5 & 49.1 & College grade \\
\hline 15 & Ranitidine & 6 & 51.8 & I0th-IIth grade \\
\hline 16 & Vitamin BI substances & 6 & 54.1 & I0th-I I th grade \\
\hline 17 & Metoprolol 50 & 6 & 54.1 & I0th-I I th grade \\
\hline 18 & Ibuprofen & 5 & 54.9 & I0th-I I th grade \\
\hline 19 & Acetaminophen + codeine & 3 & 54.9 & I0th-I I th grade \\
\hline 20 & Clidinium-C & 2 & 54.9 & I0th-I I th grade \\
\hline 21 & Alprazolam 0.5 & 7 & 56.2 & I0th-I I th grade \\
\hline 22 & Amlodipine besilate 5 & 13 & 57.9 & IOth-I I th grade \\
\hline 23 & Spironolactone & 2 & 58 & I0th-II th grade \\
\hline 24 & Cephalexin 500 & 7 & 58.6 & IOth-I I th grade \\
\hline 25 & Gemfibrozil 300 & 7 & 58.8 & I0th-I I th grade \\
\hline 26 & Folic acid & 2 & 58.9 & I0th-I I th grade \\
\hline 27 & Adult cold & 3 & 58.9 & I0th-I I th grade \\
\hline 28 & Propranolol hydrochloride 10 & 5 & 59.6 & I0th-I I th grade \\
\hline 29 & Triamterene- $\mathrm{H}$ & I & 61.5 & 8th-9th grade \\
\hline 30 & Fluoxetine hydrochloride 20 & 4 & 63.6 & 8th-9th grade \\
\hline 31 & Omeprazole 20 & 7 & 63.9 & 8th-9th grade \\
\hline 32 & Furosemide & 1 & 68.2 & 8th-9th grade \\
\hline 33 & Ferrous sulfate & I & 72.5 & 7th grade \\
\hline
\end{tabular}

Notes: $\mathrm{N}=33$. Average $=52.5$. Maximum $=72.5$. Minimum $=35.5$.

Abbreviations: FDR, Flesch-Dayani readability; PPI, patient package insert. 
antiepileptics with the average FDR $=43.4$, antidiabetics with the FDR $=45.4$ and antihistamines with the FDR $=49.1$ were ranked as the most difficult to read groups of the medications. None of the PPIs with the groupwise classification met the standard level, i.e., grade 5 or 6 (Table 3 ).

To conclude, only five (3.2\%) PPIs contained an easy to read and understandable package insert, suitable for the grade 5 or 6 , which not necessarily we should consider them as a group of drugs (Table 2). Meanwhile, the average reading ease of the group of the medicines titled "Nutritional agent and Vitamins" with the FDR $=61.8$ (Table 3 ) and a grade $=8-9$ was ranked as the standard one (Table S4). The study also pointed out a deviation on the readability level among the pharmaceutical brochures of the studied factories (Table S2).

\section{Discussion}

The PPIs are the first and the most available source of information for the patients who take the medications. The readable and understandable PPIs positively enhance the patients' knowledge and consequently help the correct use of the medications. This study evaluated the readability of the PPIs for the top-selling drugs in Iran. This was the first study of this sort to assess the readability of the package inserts in Iran. This study revealed that there is no consistency in the readability of the PPIs for the prescribed and over-the-counter drugs in Iran. The readability degree for a medicine that is manufactured by different factories varies from each other, and also, all the medicines in a particular treatment group were different in terms of their level of readability.

This study also found that neither the prescribed drugs in the specific treatment groups nor the PPIs of the over-thecounter drugs have been designed easy to understand or read. Whereas the recommended reading level for all the patient education materials is the 5 th-6th reading grade, the average reading ease level for the Persian PPIs was scored 10th-11th, i.e., FDRE score of 52.5, which is almost five times lower (difficult) than the recommended one.

The package inserts of the antidepressants followed by the nutritional agents and vitamins were the easiest comparing to other medications; however, they were graded 8th, which is two levels difficult than the standard level.

The language readability of the PPIs for the treatment of the chronic diseases, such as gastrointestinal, cardiovascular, antibacterial and anxiolytic sedatives, hypnotics and antipsychotics; anti-inflammatory drugs and antipyretics, was not suitable for the inexpert readers, while all of them are the medications listed not only as the top leading cause of death worldwide by World Health Organization (WHO) ${ }^{17}$ but also as the high-cost treatment diseases. People with such chronic

Table 2 Rate of reading ease score and grade of all pharmaceutical brochures/PPIs

\begin{tabular}{lllll}
\hline Reading ease score & Description & Predicted reading grade & Number of package inserts & Estimated percentage \\
\hline $90-100$ & Very easy & 5th grade & 1 & 0.63 \\
$80-90$ & Easy & 6th grade & 4 & 2.53 \\
$70-80$ & Fairly easy & 7th grade & 17 & 10.7 \\
$60-70$ & Standard & 8th-9th grade & 24 & 15.2 \\
$50-60$ & Fairly difficult & I0th-IIth grade & 40 & 25.3 \\
$30-50$ & Difficult & College grade & 55 & 34.8 \\
$0-30$ & Very difficult & College graduate & 17 & 10.7 \\
\hline
\end{tabular}

Abbreviation: PPI, patient package insert.

Table 3 Average reading ease score for PPIs based on the treatment group of drugs

\begin{tabular}{lllll}
\hline Order & Treatment group & Number of drugs & Number of PPI & Average $R$ score \\
\hline 1 & Nutritional agents and vitamins & 3 & 9 & 61.8 \\
2 & Gastrointestinal drugs & 3 & 14 & 56.9 \\
3 & Electrolytes & 1 & 6 & 56.9 \\
4 & Cardiovascular drugs & 13 & 66 & 52.3 \\
5 & Antidepressants & 1 & 4 & 52.3 \\
6 & Antibacterials & 2 & 9 & 52.1 \\
7 & Analgesics, anti-inflammatory drugs and antipyretics & 5 & 19 & 50.7 \\
8 & Anxiolytic sedatives, hypnotics and antipsychotics & 1 & 7 & 50.7 \\
9 & Antihistamines & 1 & 5 & 49.1 \\
10 & Antidiabetics & 2 & 15 & 45.4 \\
11 & Antiepileptics & 1 & 3 & 43.4
\end{tabular}

Abbreviation: PPI, patient package insert. 
diseases mostly tend to use the medications on their own in order to tackle the high treatment cost.

In this study, the greatest number of the PPIs and the most difficult ones belong to the cardiovascular drugs. The average score of reading ease for cardiovascular medications was 52.3 , which were graded 10th-11th (fairly difficult). However, there is a relationship between the right usage of cardiovascular drugs and patients' outcomes. Misunderstanding of the medication usage instructions and defect in intake of drugs make significant damage on health. A systematic review of hypertension drugs before 2000 also demonstrated that a few number of PPIs meet all evaluation criteria and are written in plain language. ${ }^{18}$

NSAIDs are known as the most prescribed and most used drugs through the world, which are sold with or without a prescription in the pharmacies. ${ }^{19}$ The NSAIDs help to manage the pain and the inflammation, but they have side effects on the heart, hypertension, arthritis and digestive system. The evidence indicate that there is a significant connection between the NSAIDs and the heart attack even if they are used for a short period of time and in a minimum dosage. ${ }^{20}$ Therefore, in the present study, the guidelines for this group of the medications have been written with a fairly difficult, difficult and a very difficult level through the PPIs. It should be noted that the literacy and knowledge of the patients about the correct usage of the drugs and their feedback are vital in case of any side effect and a suspicious reaction. Therefore, it is necessary that the package inserts are written in simple language and meet the literacy needs of the public community. The latest clinical findings about a specific drug should be mentioned in the package inserts. The PPIs need to be inspected in certain intervals, for instance annually. It is suggested to add the latest discovered information leaflet to the medicine box/packs when they are delivered to the patients or when the prescription is booked in a pharmacy. Owing to some difficulties of the ever-changing nature of the up-to-date information about the medicines, adding a new copy of the PPI or information to the prescriptions of the patients might be a feasible solution.

The evaluation of readability of the patient leaflets in the UK shows that the package leaflets reading grade was $<8$ and were well designed. ${ }^{21}$

Based on the average FDR score, the reading ease of the diabetic medicines' PPIs in the present study was graded difficult. A study of the same group of the medicine (diabetic) in Qatar also suggested that the average reading ease of the diabetic medicines is 37.7 ( \pm 15.85$)$, which is very difficult. The authors of that study also found that only $2.2 \%$ of the
PPIs possess the acceptable readability level. ${ }^{7}$ In India also, it was revealed that the diabetic medicines' PPIs are unclear and led to the medication misuse. ${ }^{22}$

The proton pump inhibitor drugs such as omeprazole are the widely used medicines, and they have many side effects. A recent research group even revealed that although their use around the world is growing and expanding, their use is dangerous and even a lower dose and a shorter period time of intake may lead to death. This study group recommended that the use of these drugs must be under the physician's watch and full control. ${ }^{23}$

On average, the reading ease of the Iranian most prescribed and top-selling drugs was approximately five times difficult than the recommended readability score for the patients. The readability of the PPIs of the medicines was inconsistent from one drug to another, as well as from one factory to another. It means that there is no audit for the package inserts' readability and content. This is the first study about the readability of the Iranian drugs' PPI; however, Ahmadzadeh and Ahmadzadeh ${ }^{10}$ also studied the readability of the patient leaflets distributed in the hospitals and found that the majority of such information resources have been provided at the college level, based on the Flesh reading ease formula, and exceed the patients' understandability and health literacy. In the USA also, study of $\sim 63$ PPIs showed that PPIs are provided higher than the recommended level in $~ 10$ th grade and need assessment and change. ${ }^{24}$ Earlier studies also suggested the same significant message that the readability of the PPIs are higher than the patients' level of literacy. ${ }^{20}$ Charbonneau ${ }^{13}$ assessed the readability of the hormone therapy PPIs and found them to be higher than the patients' health literacy level of US population.

However, in marked contrast, the readability assessment of the PPIs in Germany revealed that PPIs' readability is generally suitable for everyone. ${ }^{25}$ The majority of the research outputs regarding the readability of the PPIs indicate that reading ease score of the PPIs is higher than the reading and understanding level of the people. The findings of this work agree with the earlier studies conducted by Al-Aqee ${ }^{26}$ and Sawalha et al. ${ }^{27}$ The findings also verify that the readability of the written drug information is higher than the readers' understanding ability. ${ }^{2,13}$

This research along with the previous researches points out that the most obvious right of the patients that is a proper access to the understandable medical information is overlooked in Iran, as well as the most part of the world, even in the developed countries. The readability level of a considerable number of the PPIs in Iran is poor for the inexpert people. 
There is no auditing carried out to make sure that the package inserts are readable and comprehensible, which in a way leads to the drug misuse among the people and provides opportunity for the medication trade under advertisement without evidence.

Since the treatment cost is extremely high in Iran, the people tend to use the medications on their own or simply follow the old prescriptions. When the PPIs are poor in terms of their information and their readability, they will incline to use the inaccurate advertised drug information. To solve this problem, the Food and Drug Administration and the related organizations must intervene through the continuous assessment of PPIs for better readability and information content. The extension of the drug licenses for the pharmaceutical companies should be subject to the provision of the PPIs, considering the continuous control of the quality and easy to read contents of the PPIs.

\section{Acknowledgments}

We thank all the pharmacy managers and pharmaceutical companies that helped us in collecting the package inserts. This study is funded by Tabriz University of Medical Sciences. The name of the drug manufacturing companies is kept confidential under the license of the research ethical committee of Tabriz University of Medical Sciences.

\section{Disclosure}

The authors report no conflicts of interest in this work.

\section{References}

1. Singh KR, Munshi R, Arora D. Assessment of the degree of awareness among physicians and patients about drug package inserts. Int J Pharm Sci Res. 2016;7(3):1338.

2. Vander Stichele RH. Impact of written drug information in patient package inserts. Acceptance and benefit/risk perception. Gent. Academia Press Scientific Publishers. 2004.

3. Dass AS, Sarala N, Bhuvana K. Analysis of package inserts of drugs utilized in a tertiary care hospital. J Young Pharm. 2016;8(3):275.

4. Gupta V, Pathak S. Assessment of awareness and knowledge about package inserts amongst medical students: a questionnaire based study. IOSR J Pharm. 2012;2(2):215-217.

5. Piñero-López MÁ, Modamio P, Lastra CF, Mariño EL. Readability assessment of package inserts of biological medicinal products from the European medicines agency website. Drug Saf. 2014;37(7):543-554.

6. Ramdas D, Chakraborty A, Swaroop H, Faizan S, Kumar P, Srinivas B. A study of package inserts in southern India. J Clin Diag Res. 2013;7(11):2475.
7. Munsour EE, Awaisu A, Hassali MAA, Darwish S, Abdoun E. Readability and comprehensibility of patient information leaflets for antidiabetic medications in Qatar. J Pharm Technol. 2017;33(4):128-136.

8. Fuchs J, Hippus M, Schaefer M. A survey of package inserts use by patients. Hosp Pharm. 2005:29-31.

9. Amin ME, Chewning BA, Wahdan AM. Sources of drug information for patients with chronic conditions in Alexandria, Egypt. Int J Pharm Prac. 2011;19(1):13-20.

10. Ahmadzadeh Z, Ahmadzadeh K. Evaluation of readability of patient education sources distributed in Shiraz health centers using FleschDayani. Adv Med Info. 2014;2(3):43-51.

11. Singh G, Triadafilopoulos G. Epidemiology of NSAID induced gastrointestinal complications. J Rheumatol Suppl. 1999;56:18-24.

12. Sulaiman W, Seung OP, Ismail R. Patient's knowledge and perception towards the use of non-steroidal anti-inflammatory drugs in rheumatology clinic Northern Malaysia. Oman Med J. 2012;27(6):505.

13. Charbonneau DH. Health literacy and the readability of written information for hormone therapies. J Midwifery Women Health. 2013;58(3):265-270.

14. Weis BD. Health Literacy: A Manual for Clinicians. Chicago: American Medical Association, American Medical Foundation; 2003.

15. Arastoopoor S. The Feasibility Determination to Improve Readability Basic Concept in the Field of Specialized Data Recovery in Persian: Case Study of Computer Science. Shiraz: Persepolis; 1391.

16. Flesch RF. How to write plain English: A book for lawyers and consumers. HarperCollins; 1979.

17. World Health Organization (WHO). Top 10 Causes of Death. Geneva: WHO; 2015.

18. Fitzmaurice D, Adams J. A systematic review of patient information leaflets for hypertension. J Hum Hypertens. 2000;14(4):259.

19. Wilcox CM, Shalek KA, Cotsonis G. Striking prevalence of over-thecounter nonsteroidal anti-inflammatory drug use in patients with upper gastrointestinal hemorrhage. Arch Intern Med. 1994;154(1):42-46.

20. Bally M, Dendukuri N, Rich B, et al. Risk of acute myocardial infarction with NSAIDs in real world use: Bayesian meta-analysis of individual patient data. BMJ. 2017;357:j1909.

21. Williamson JML, Martin A. Analysis of patient information leaflets provided by a district general hospital by the Flesch and Flesch-Kincaid method. Int J Clin Pract. 2010;64(13):1824-1831.

22. Ramadas D, Chakraborty A. Analysis of package inserts of anti-diabetic medications in India. Int J Basic Clin Pharmacol. 2016;5(5):2240-2243.

23. Xie Y, Bowe B, Li T, Xian H, Yan Y, Al-Aly Z. Risk of death among users of proton pump inhibitors: a longitudinal observational cohort study of United States veterans. BMJ Open. 2017;7(6):e015735.

24. Basara LR, Juergens JP. Patient package insert readability and design: PPIs produced by associations are better than those of pharmaceutical manufacturers and commercial vendors) but all need improvement. Am Pharm. 1994;34(8):48-53.

25. Beime B, Menges K. Does the requirement of readability testing improve package leaflets? Evaluation of the 100 most frequently prescribed drugs in Germany marketed before 2005 and first time in 2007 or after. Pharm Regul Affairs. 2012;1:102.

26. Al-Aqeel SA. Evaluation of medication package inserts in Saudi Arabia. Drug Healthc Patient Saf. 2012;4:33.

27. Sawalha A, Sweileh W, Zyoud S, Jabi S. Comparative analysis of patient package inserts of local and imported anti-infective agents in Palestine. Libyan J Med. 2008;3(4):1-7.

28. Dayani MH. [A criteria for assessing the Persian texts' readability]. J Soc Sci Hum. 2000;10:35-48. Persian. 


\section{Supplementary materials}

Table SI List of high-selling drugs announced by the Social Security Organization in Iran

Drugs

Losartan potassium 25

Metformin hydrochloride 500

Glibenclamide

Metoprolol 50

Diclofenac 25

Ranitidine

Calcium supplements

Amlodipine besylate 5

Nitroglycerin 2.6

Adult cold

Nitroglycerin 6.4

Propranolol hydrochloride 10

Amoxicillin 500

Omeprazole 20

Acetaminophen + codeine

Captopril 25

Clidinium-C

Diclofenac 50

Ferrous sulfate

Folic acid

Furosemide

Hydrochlorothiazide

Ibuprofen

Spironolactone

Triamterene-H

Sodium valproate

Fluoxetine hydrochloride 20

Vitamin BI substances 300

Alprazolam 0.5

Loratadine 10

Losartan potassium 50

Cephalexin 500

Gemfibrozil 300

Table S2 Readability score for all I 58 package inserts

\begin{tabular}{lll}
\hline Order & Drugs' generic name & FDR score \\
\hline 1 & Acetaminophen I & 42 \\
2 & Acetaminophen 2 & 74 \\
3 & Acetaminophen 3 & 48.8 \\
4 & Adult cold I & 56.4 \\
5 & Adult cold 2 & 80.1 \\
6 & Adult cold 3 & 40.3 \\
7 & Alprazolam I & 42 \\
8 & Alprazolam 2 & 45.4 \\
9 & Alprazolam 3 & 48.8 \\
10 & Alprazolam 4 & 57.2 \\
11 & Alprazolam 5 & 76.7 \\
12 & Alprazolam 6 & 55.6 \\
13 & Alprazolam 7 & 67.4 \\
14 & Amlodipin I & 63.2 \\
15 & Amlodipin I0 & 59.8 \\
16 & Amlodipin I & 45.4 \\
17 & Amlodipin I & 77.4 \\
\hline
\end{tabular}


Table S2 (Continued)

\begin{tabular}{|c|c|c|}
\hline Order & Drugs' generic name & FDR score \\
\hline 18 & Amlodipin I3 & 48.8 \\
\hline 19 & Amlodipin 2 & 42.9 \\
\hline 20 & Amlodipin 3 & 70.8 \\
\hline 21 & Amlodipin 4 & 35.2 \\
\hline 22 & Amlodipin 5 & 46.2 \\
\hline 23 & Amlodipin 6 & 45.4 \\
\hline 24 & Amlodipin 7 & 69 \\
\hline 25 & Amlodipin 8 & 56.4 \\
\hline 26 & Amlodipin 9 & 82.6 \\
\hline 27 & Amoxicillin I & 58 \\
\hline 28 & Amoxicillin 2 & 33.4 \\
\hline 29 & Calcium dl & 9.9 \\
\hline 30 & Calcium d2 & 11.6 \\
\hline 31 & Calcium d3 & 7.3 \\
\hline 32 & Calcium d4 & 41.2 \\
\hline 33 & Calcium d5 & 48.7 \\
\hline 34 & Calcium d6 & 97.9 \\
\hline 35 & Captopril I & 45.4 \\
\hline 36 & Captopril 2 & 37.8 \\
\hline 37 & Captopril 3 & 29.3 \\
\hline 38 & Cefalexin I & 71.6 \\
\hline 39 & Cefalexin 2 & 62.3 \\
\hline 40 & Cefalexin 3 & 46.2 \\
\hline 41 & Cefalexin 4 & 51.2 \\
\hline 42 & Cefalexin 5 & 56.4 \\
\hline 43 & Cefalexin 6 & 55.6 \\
\hline 44 & Cefalexin 7 & 66.6 \\
\hline 45 & Clidinium Cl & 59.7 \\
\hline 46 & Clidinium C2 & 46.3 \\
\hline 47 & Clidinium C3 & 58.9 \\
\hline 48 & Captopril 4 & 29.3 \\
\hline 49 & Diclofenac 25-I & 32.7 \\
\hline 50 & Diclofenac 25-2 & 32.7 \\
\hline 51 & Diclofenac 25-3 & 67.4 \\
\hline 52 & Diclofenac 25-4 & 63.2 \\
\hline 53 & Diclofenac 25-5 & 44.6 \\
\hline 54 & Diclofenac 50-I & 44.6 \\
\hline 55 & Diclofenac 50-2 & 32.7 \\
\hline 56 & Diclofenac 50-3 & 32.7 \\
\hline 57 & Ferrous sulfate & 72.5 \\
\hline 58 & Fluoxetine I & 52.2 \\
\hline 59 & Fluoxetine 2 & 72.9 \\
\hline 60 & Fluoxetine 3 & 60.6 \\
\hline 61 & Fluoxetine 4 & 69.1 \\
\hline 62 & Furosemide & 68.2 \\
\hline 63 & Folic acid I & 55.6 \\
\hline 64 & Folic acid 2 & 62.2 \\
\hline 65 & Gemfibrozil I & 73.3 \\
\hline 66 & Gemfibrozil 2 & 68.2 \\
\hline 67 & Gemfibrozil 3 & 58.9 \\
\hline 68 & Gemfibrozil 4 & 47.1 \\
\hline 69 & Gemfibrozil 5 & 34.4 \\
\hline 70 & Gemfibrozil 6 & 53 \\
\hline 7I & Gemfibrozil 7 & 76.7 \\
\hline 72 & Glibenclamide I & 42.9 \\
\hline 73 & Glibenclamide 2 & 53 \\
\hline 74 & Glibenclamide 3 & 42. 9 \\
\hline
\end{tabular}


Table S2 (Continued)

\begin{tabular}{|c|c|c|}
\hline Order & Drugs' generic name & FDR score \\
\hline 75 & Glibenclamide 4 & 56.4 \\
\hline 76 & Glibenclamide 5 & 50.9 \\
\hline 77 & Hydrochlorothiazide I & 42 \\
\hline 78 & Hydrochlorothiazide 2 & 51.3 \\
\hline 79 & Ibuprofen I & 64.9 \\
\hline 80 & Ibuprofen 2 & 59.8 \\
\hline 81 & Ibuprofen 3 & 47.1 \\
\hline 82 & Ibuprofen 4 & 47.9 \\
\hline 83 & Loratadine I & 37.8 \\
\hline 84 & Loratadine 2 & 17.5 \\
\hline 85 & Loratadine 3 & 64.9 \\
\hline 86 & Loratadine 4 & 72.5 \\
\hline 87 & Loratadine 5 & 53 \\
\hline 88 & Losartan potassium 25-I & 13.3 \\
\hline 89 & Losartan potassium 25-2 & 43.7 \\
\hline 90 & Losartan potassium 25-3 & 42.9 \\
\hline 91 & Losartan potassium 25-4 & 50.5 \\
\hline 92 & Losartan potassium 25-5 & 69.9 \\
\hline 93 & Losartan potassium 25-6 & 41 \\
\hline 94 & Losartan potassium 50-I & 13.3 \\
\hline 95 & Losartan potassium 50-2 & 43.7 \\
\hline 96 & Losartan potassium $50-3$ & 42.9 \\
\hline 97 & Losartan potassium 50-4 & 50.5 \\
\hline 98 & Losartan potassium 50-5 & 69.9 \\
\hline 99 & Losartan potassium 50-6 & 41 \\
\hline 100 & Metformin hydrochloride I & 56.42 \\
\hline 101 & Metformin hydrochloride 10 & 28.5 \\
\hline 102 & Metformin hydrochloride 2 & 44.6 \\
\hline 103 & Metformin hydrochloride 3 & 45.4 \\
\hline 104 & Metformin hydrochloride 4 & 42 \\
\hline 105 & Metformin hydrochloride 5 & 23.4 \\
\hline 106 & Metformin hydrochloride 6 & 45.4 \\
\hline 107 & Metformin hydrochloride 7 & 38.6 \\
\hline 108 & Metformin hydrochloride 8 & 59.8 \\
\hline 109 & Metformin hydrochloride 9 & 33.6 \\
\hline 110 & Metoprolol I & 52.2 \\
\hline 111 & Metoprolol 2 & 51.3 \\
\hline 112 & Metoprolol 3 & 47.9 \\
\hline 113 & Metoprolol 4 & 42. 9 \\
\hline 114 & Metoprolol 5 & 60.6 \\
\hline 115 & Metoprolol 6 & 69.9 \\
\hline 116 & Nitroglycerin 2.6-I & 28.5 \\
\hline 117 & Nitroglycerin $2.6-2$ & 42 \\
\hline 118 & Nitroglycerin $2.6-3$ & 70.8 \\
\hline 119 & Nitroglycerin $2.6-4$ & 59.8 \\
\hline 120 & Nitroglycerin $2.6-5$ & 47.9 \\
\hline 121 & Nitroglycerin $2.6-6$ & 70.7 \\
\hline 122 & Nitroglycerin $2.6-7$ & 18.3 \\
\hline 123 & Nitroglycerin 6.4-I & 18.3 \\
\hline 124 & Nitroglycerin 6.4-2 & 42 \\
\hline 125 & Nitroglycerin $6.4-3$ & 70.8 \\
\hline 126 & Nitroglycerin $6.4-4$ & 59.8 \\
\hline 127 & Nitroglycerin 6.4-5 & 47.9 \\
\hline 128 & Nitroglycerin 6.4-6 & 28.5 \\
\hline 129 & Omeprazole I & 83.5 \\
\hline 130 & Omeprazole 2 & 83.5 \\
\hline 131 & Omeprazole 3 & 54.7 \\
\hline
\end{tabular}

(Continued) 
Table S2 (Continued)

\begin{tabular}{|c|c|c|}
\hline Order & Drugs' generic name & FDR score \\
\hline 132 & Omeprazole 4 & 58.1 \\
\hline 133 & Omeprazole 5 & 23.4 \\
\hline 134 & Omeprazole 6 & 72.49 \\
\hline 135 & Omeprazole 7 & 71.6 \\
\hline 136 & Propranolol hydrochloride I & 76.7 \\
\hline 137 & Propranolol hydrochloride 2 & 53.9 \\
\hline 138 & Propranolol hydrochloride 3 & 46.2 \\
\hline 139 & Propranolol hydrochloride 4 & 60.6 \\
\hline 140 & Propranolol hydrochloride 5 & 60.6 \\
\hline |4| & Ranitidine I & 42 \\
\hline 142 & Ranitidine 2 & 49.5 \\
\hline 143 & Ranitidine 3 & 37.8 \\
\hline 144 & Ranitidine 4 & 51.2 \\
\hline 145 & Ranitidine 5 & 56.4 \\
\hline 146 & Ranitidine 6 & 74.2 \\
\hline 147 & Spironolactone I & 64.9 \\
\hline 148 & Spironolactone 2 & 51.2 \\
\hline 149 & Triamterene-H & 61.5 \\
\hline 150 & Sodium valproate I & 15.8 \\
\hline 151 & Sodium valproate 2 & 55.6 \\
\hline 152 & Sodium valproate 3 & 58.9 \\
\hline 153 & Vitamin BII & 26.8 \\
\hline 154 & Vitamin $B 12$ & 57.3 \\
\hline 155 & Vitamin $\mathrm{B} / 3$ & 58 \\
\hline 156 & Vitamin BI4 & 53.9 \\
\hline 157 & Vitamin BI5 & 66.5 \\
\hline 158 & Vitamin BI6 & 62.3 \\
\hline
\end{tabular}

Abbreviation: FDR, Flesch-Dayani reading.

Table S3 List of all 33 drugs with their treatment group

\begin{tabular}{lll}
\hline Order & Generic name & Medication group \\
\hline 1 & Losartan potassium & Cardiovascular drugs \\
2 & Metformin hydrochloride & Antidiabetics \\
3 & Glibenclamide & Antidiabetics \\
4 & Metoprolol & Cardiovascular drugs \\
5 & Diclofenac & Analgesics, anti-inflammatory drugs and antipyretics \\
6 & Ranitidine & Gastrointestinal drugs \\
7 & Calcium supplements & Electrolytes \\
8 & Amlodipine besylate & Cardiovascular drugs \\
9 & Nitroglycerin & Cardiovascular drugs \\
10 & Adult cold & Analgesics, anti-inflammatory drugs and antipyretics \\
11 & Nitroglycerin & Cardiovascular drugs \\
12 & Propranolol hydrochloride & Cardiovascular drugs \\
13 & Amoxicillin & Antibacterials \\
14 & Omeprazole & Gastrointestinal drugs \\
15 & Acetaminophen + codeine & Analgesics, anti-inflammatory drugs and antipyretics \\
16 & Captopril & Cardiovascular drugs \\
17 & Clidinium-C & Gastrointestinal drugs \\
18 & Diclofenac & Analgesics, anti-inflammatory drugs and antipyretics \\
19 & Ferrous sulfate & Nutritional agents and vitamins \\
20 & Folic acid & Nutritional agents and vitamins \\
21 & Furosemide & Cardiovascular drugs \\
22 & Hydrochlorothiazide & Cardiovascular drugs \\
23 & lbuprofen & Analgesics, anti-inflammatory drugs and antipyretics \\
24 & Spironolactone & Cardiovascular drugs \\
\hline & &
\end{tabular}


Table S3 (Continued)

\begin{tabular}{lll}
\hline Order & Generic name & Medication group \\
\hline 25 & Triamterene-H & Cardiovascular drugs \\
26 & Sodium valproate & Antiepileptics \\
27 & Fluoxetine hydrochloride & Antidepressants \\
28 & Vitamin BI substances & Nutritional agents and vitamins \\
29 & Alprazolam & Anxiolytic sedatives, hypnotics and antipsychotics \\
30 & Loratadine & Antihistamines \\
31 & Losartan potassium & Cardiovascular drugs \\
32 & Cephalexin & Antibacterials \\
33 & Gemfibrozil & Cardiovascular drugs \\
\hline
\end{tabular}

Table S4 Flesch reading ease table

\begin{tabular}{lll}
\hline Reading ease score & Description & Predicted reading grade \\
\hline $90-100$ & Very easy & 5th grade \\
$80-90$ & Easy & 6th grade \\
$70-80$ & Fairly easy & 7th grade \\
$60-70$ & Standard & 8th-9th grade \\
$50-60$ & Fairly difficult & 10th-1Ith grade \\
$30-50$ & Difficult & College grade \\
$0-30$ & Very difficult & College graduate \\
\hline
\end{tabular}

\section{Publish your work in this journal}

Drug, Healthcare and Patient Safety is an international, peer-reviewed open access journal exploring patient safety issues in the healthcare continuum from diagnostic and screening interventions through to treatment, drug therapy and surgery. The journal is characterized by the rapid reporting of reviews, original research, clinical, epidemiological and

\section{Dovepress}

post-marketing surveillance studies, risk management, health literacy and educational programs across all areas of healthcare delivery. The manuscript management system is completely online and includes a very quick and fair peer-review system. Visit http://www.dovepress.com/ testimonials.php to read real quotes from published authors.

Submit your manuscript here: https://www.dovepress.com/drug-healthcare-and-patient-safety-journal 